\title{
Phytophthora ramorum in Canada: Evidence for Migration Within North America and from Europe
}

\author{
Erica M. Goss, Meg Larsen, Annelies Vercauteren, Sabine Werres, Kurt Heungens, and Niklaus J. Grünwald
}

First, second, and sixth authors: Horticultural Crops Research Laboratory, United States Department of Agriculture-Agricultural Research Service, Corvallis, OR; third and fifth authors: Institute for Agricultural and Fisheries Research (ILVO), Plant Sciences Unit-Crop Protection, Merelbeke, Belgium; and fourth author: Julius Kuehn Institute-Federal Research Centre for Cultivated Plants, Institute for Plant Protection in Horticulture and Forests, Braunschweig, Germany. Accepted for publication 16 September 2010.

\begin{abstract}
Goss, E. M., Larsen, M., Vercauteren, A., Werres, S., Heungens, K., and Grünwald, N. J. 2011. Phytophthora ramorum in Canada: Evidence for migration within North America and from Europe. Phytopathology 101:166-171.

Phytophthora ramorum, the cause of sudden oak death on oak and ramorum blight on woody ornamentals, has been reported in ornamental nurseries on the West Coast of North America from British Columbia to California. Long-distance migration of $P$. ramorum has occurred via the nursery trade, and shipments of host plants are known to have crossed the U.S.-Canadian border. We investigated the genotypic diversity of $P$. ramorum in Canadian nurseries and compared the Canadian population

with U.S. and European nursery isolates for evidence of migration among populations. All three of the $P$. ramorum clonal lineages were found in Canada but, unexpectedly, the most common was the NA2 lineage. The NA1 clonal lineage, which has been the most common lineage in U.S. nurseries, was found relatively infrequently in Canada, and these isolates may have been the result of migration from the United States to Canada. The EU1 lineage was observed almost every year and shared multilocus genotypes with isolates from Europe and the United States. Estimation of migration rates between Europe and North America indicated that migration was higher from Europe to North America than vice versa, and that unidirectional migration from Europe to North America was more likely than bidirectional migration.
\end{abstract}

The global migration of plant pathogens, mediated by human activity, threatens native plant communities and commercial interests (5). An analysis of point-of-entry data from the United States Department of Agriculture Animal and Plant Health Inspection Service (USDA-APHIS) showed that, between 1984 and 2000 , there were 4,000 to 8,097 records of plant pathogen interceptions per year, often associated with ornamental plants and propagative material in cargo and the baggage of international travelers (22). The oomycete Phytophthora ramorum is suspected to have been introduced to and successfully established in the United States a minimum of three times $(12,16)$. P. ramorum causes ramorum blight and sudden oak death, a disease associated with extensive mortality to tanoak and coast live oak in coastal forests and woodlands in northern California and southern Oregon $(25,26)$. The long-distance movement of this pathogen can likely be attributed to its broad host range, currently with 45 proven hosts and 72 additional associated hosts that are regulated by the USDA as nursery stock, including popular woody ornamentals such as rhododendron and camellia. Thus, $P$. ramorum is also found in nurseries and gardens in North America and Europe. The pathogen has been costly to the nursery industry due to its regulatory impact, particularly for those nurseries that have been found to be infected with $P$. ramorum (10).

Corresponding author: N. J. Grünwald;

E-mail address: Nik.Grunwald@ ars.usda.gov

* The $e$-Xtra logo stands for "electronic extra" and indicates that the online version contains three supplemental tables. Figure 2 appears in color online.

doi:10.1094/PHYTO-05-10-0133

This article is in the public domain and not copyrightable. It may be freely reprinted with customary crediting of the source. The American Phytopathological Society, 2011.
Three clonal lineages of $P$. ramorum have been described $(12,17,19)$ and given the names NA1, NA2, and EU1 (15). The NA1 and NA2 lineages are currently only known in North America. The EU1 lineage was initially found in Europe but is now also found in North America. Nurseries in the western United States have been shown to be infested with all three lineages. To date, NA2 has been isolated from infected nursery stock in Washington and California and EU1 from nurseries in Oregon, Washington, and California. The NA1 lineage has a wider distribution as a result of shipments of infected material from the three West Coast states (13). Shipments of infected material from California, Oregon, and Washington to British Columbia, Canada and vice versa have also occurred (13). Only a handful of isolates from Canada have been genotyped for clonal lineage, with EU1 and NA2 being reported based on polymerase chain reaction (PCR) restriction fragment length polymorphism and allele-specific PCR $(4,8)$.

Microsatellite (short-sequence repeat) markers have revealed genotypic diversity within the NA1 and EU1 lineages and have provided valuable insight into the population structure, migration, and evolution of $P$. ramorum in forest and nursery environments $(13,17,21,23,24,28)$. To date, there has not been a genetic survey of $P$. ramorum isolated from Canadian nurseries. Here, we examine the genotypic diversity of Canadian isolates of $P$. ramorum. Our objectives were to assess the relative frequencies of the three lineages, quantify genetic diversity within lineages, and compare the variation at the typed microsatellite loci in Canada to that of $P$. ramorum reported in nursery settings in the United States and Europe. We examined the data for evidence of detectable migration of $P$. ramorum between Canada and the United States, and estimated migration rates of the EU1 clonal lineage between European and North American populations. In particular, we tested the hypothesis that migration has been unidirectional from Europe to North America, which is based on the detection of this 
lineage in Europe approximately 10 years before it was detected in North America.

\section{MATERIALS AND METHODS}

Isolates. Canadian isolates genotyped were a random sample from the Canadian Food Inspection Agency's P. ramorum isolate collection, kindly provided by Stephan Brière (Supplemental Table S1). The isolates were collected from 31 sites from 2003 to 2008 , including retail and wholesale nurseries. EU1 isolates from Europe were those examined by Werres and Kaminski (29) and isolates from the United States included those previously genotyped by Goss et al. (13) and recent finds from U.S. nurseries (N. J. Grünwald, unpublished data).

All isolates were handled following the standard operating procedures associated with corresponding USDA-APHIS permits and an exemption from the Director of the Oregon Department of Agriculture for work with $P$. ramorum under containment conditions.

Mating type determination. Mating type was determined for $P$. ramorum isolates from Canada using the protocol detailed by Brasier and Kirk (6). Each isolate was paired with known $P$. ramorum isolates PR-06-009 (A1, Oregon nursery) and either PR06-010 (A2, Oregon forest) or PR-08-103 (A2, California nursery). Some isolates did not produce oospores in either pairing; this result is indicated by 'nd' (not determined) in Supplemental Table S1.

Microsatellite genotyping. Nine microsatellite loci were genotyped that had previously shown variation among isolates within the $P$. ramorum clonal lineages: PrMS39, PrMS43, PrMS45 (24), 18, 64, 82a (17), 82b (17,28), ILVOPrMS145a, and ILVOPrMS145c (28). These loci are also differentiated between lineages. Three additional loci that are invariable within lineagesPrMS6, PrMS9C3 (24), and ILVOPrMS145b (28)-were also genotyped. Genotyping was conducted as previously described $(13,28)$. All loci were genotyped in the Grünwald lab with the exception of PrMS145a-c, which were genotyped in the Heungens lab for EU1 isolates only. For Canadian isolates only, this locus was also genotyped by the Grünwald lab. Sizes of alleles differed between the labs as a result of different laboratory methods.

Analysis. Vercauteren et al. (28) determined the assignment of alleles amplified by microsatellite primers 82 and ILVOPrMS 145 to two and three loci, respectively, for EU1 and NA1 isolates. They also determined that the primers PrMS39 and PrMS43 amplify one locus each, not two loci as reported in previous publications $(13,20,21,23,24)$. Alleles produced by the 82 primers have not been assigned to loci for NA2 isolates, which also appear to produce one more allele than isolates from the other two lineages (five for NA2 versus four for NA1 and EU1).

NA1 isolates from Canada were compared with NA1 multilocus genotypes observed in a sample of 155 isolates from nurseries in California, Oregon, and Washington (13). Isolates from other U.S. states were not included because shipments of $P$. ramorum-infected plants between Canada and other states have not been documented (13). U.S. NA1 multilocus genotypes were based on loci PrMS39, PrMS43, PrMS45, 18, and 64 only; therefore, comparisons among NA1 isolates used only this subset of loci. NA2 isolates were likewise compared with a more limited number of NA2 isolates from U.S. nurseries (13). A minimum spanning network was constructed from genotypes of NA1 isolates from Canada, Oregon, Washington, and California. Genetic distances were calculated using the method of Bruvo et al. (7), which incorporates microsatellite repeat number. MINSPNET (9) was used to generate minimum spanning networks from genetic distance matrices. All tied trees were included in the network, which was visualized using the neato program in the Graphviz package (11). Two isolates that appeared to exhibit mitotic recombination rather than stepwise mutation at PrMS45 and isolates with null alleles were excluded because they produced large genetic distances between genotypes and did not qualitatively change the relationships between Canadian and U.S. isolates. EU1 isolates from Canada were compared with EU1 isolates from Europe and from California and Oregon in the United States. A minimum spanning network was produced, as for the NA1 isolates.

Multilocus genotypic diversity was estimated using Stoddart and Taylor's index $G(27)$ and multilocus genotypic evenness (the distribution of genotypes in a sample) using the index $E_{5}(14,18)$. Bootstrap confidence intervals were calculated for each index using an SAS macro (14).

We estimated migration of the EU1 lineage between Europe and North America, and tested the hypothesis that migration has been unidirectional from Europe to North America using the program Migrate, version 3.03 (1,3). Both maximum likelihood analysis (ML) and Bayesian inference (BI) were used to estimate theta $(4 N \mu)$ and the mutation-scaled migration rate $(M=m / \mu)$ for each population, where $N$ is the effective population size, $\mu$ is the mutation rate per locus per generation, and $\mathrm{m}$ is the migration rate per generation. The Brownian motion approximation of the stepwise mutation model was used for all runs. For ML estimates, we initially used 10 short chains of $1 \times 10^{4}$ steps from which 500 genealogies were sampled, followed by two long chains of $2 \times$ $10^{6}$ steps from which $1 \times 10^{5}$ genealogies were sampled. BI used one long chain of $2 \times 10^{7}$ steps from which $1 \times 10^{6}$ genealogies were sampled. Three independent runs were performed using BI and slightly different maximums were used for the prior distributions in each run. Priors for theta were uniform from 0 to 10 , 20 , and 50 and priors for migration rate (M) were 0 to 50,100 , and 100 , respectively, in the three runs. All chains used a burn-in of $1 \times 10^{4}$ genealogies and static heating. Initial parameter values were obtained by Fst. Migration rates obtained from the ML runs were inconsistent among runs and different from the BI runs. Indications were that the ML runs were not searching the parameter space efficiently. Therefore, the average parameter estimates from the BI runs were used as initial values in long ML runs to test our hypothesis of unidirectional migration (2). Two replicate runs estimated all four parameters (theta for each population and migration in each direction) whereas two additional runs set migration from North America to Europe to zero. These runs each used a single long chain of $1.4 \times 10^{8}$ steps, recording every 20 steps. Resulting likelihoods were compared using the likelihood ratio test and Akaike's information criterion (AIC).

\section{RESULTS}

Nearly $75 \%$ of $P$. ramorum isolates from Canadian nurseries were of the NA2 clonal lineage (44 of 59 isolates) (Table 1), representing 26 of 31 sites (Fig. 1; Supplemental Table S1). Of the remaining isolates, five were NA1 and ten EU1. The EU1 lineage was found in samples from 2003-05, 2007, and 2008, NA1 was found in 2004 and 2006, and NA2 was observed from 2004-08 (Fig. 1).

All but two isolates had host information to genus. $P$. ramorum was most frequently isolated from Rhododendron spp., while Camellia, Rhododendron, and Viburnum spp. hosted multiple lineages (Table 2). Camellia spp. hosted NA1 and NA2, Viburnum spp. EU1 and NA2, and Rhododendron spp. were infected by all three lineages. Four sites were represented by isolates collected from more than one host genus: site A had infected Camellia spp. in 2004 and Rhododendron spp. in 2006 (NA1) and Camellia and Kalmia spp. in 2008 (NA2); site Q had Kalmia and Syringa spp. (NA2); site R had Camellia and Pieris spp. (NA2); and site P had Viburnum and Cornus spp. (EU1).

All EU1 isolates that produced oospores were the A1 mating type and all NA1 and NA2 isolates that produced oospores were 
TABLE 1. Population genotypic diversity statistics by clonal lineage and location

\begin{tabular}{|c|c|c|c|c|c|}
\hline Lineage & Location $^{\mathrm{a}}$ & Isolates & $\mathrm{MGs}^{\mathrm{b}}$ & Stoddart \& Taylor's G $(90 \% \text { CI })^{\mathrm{c}}$ & $\mathrm{E} 5(90 \% \mathrm{CI})^{\mathrm{c}}$ \\
\hline \multirow[t]{4}{*}{$\mathrm{NA} 1^{\mathrm{d}}$} & British Columbia, Canada & 5 & 2 & $1.47(0.95-2.08)$ & $0.72(0.46-0.83)$ \\
\hline & California, United States & 36 & 9 & $2.85(1.86-3.88)$ & $0.54(0.35-0.59)$ \\
\hline & Oregon, United States & 24 & 12 & $7.78(7.13-11.32)$ & $0.78(0.64-0.88)$ \\
\hline & Washington, United States & 95 & 34 & $17.52(16.84-22.99)$ & $0.73(0.63-0.78)$ \\
\hline \multirow[t]{2}{*}{$\mathrm{NA} 2^{\mathrm{d}}$} & British Columbia, Canada & 44 & 1 & $\ldots$ & $\ldots$ \\
\hline & Washington, United States & 17 & 2 & $1.12(0.90-1.33)$ & $0.50(0.32-0.56)$ \\
\hline \multirow[t]{4}{*}{$\mathrm{EU} 1^{\mathrm{e}}$} & British Columbia, Canada & 10 & 4 & $2.78(2.14-3.98)$ & $0.80(0.61-0.94)$ \\
\hline & California, United States & 16 & 2 & $1.97(1.82-2.31)$ & $0.98(0.91-1.00)$ \\
\hline & Oregon, United States & 26 & 2 & $1.99(1.89-2.22)$ & $0.99(0.95-1.00)$ \\
\hline & Europe $^{\mathrm{f}}$ & 77 & 12 & $1.63(1.30-1.95)$ & $0.34(0.27-0.34)$ \\
\hline
\end{tabular}

a Nursery isolates only.

b Number of multilocus genotypes (MGs).

${ }^{c}$ Confidence intervals (CIs) were based on 2,000 bootstrap samples.

${ }^{\mathrm{d}}$ Statistics were calculated using a reduced sample of loci (see text). U.S. isolates are those in Goss et al. (13).

e Isolates include European isolates via Werres, U.S. isolates from Goss et al. (13) (2005-07) plus 2008 collections from U.S. nurseries.

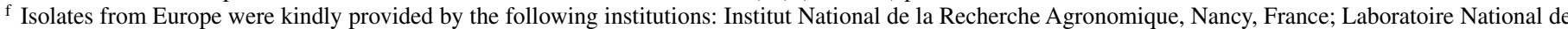
la Protection des Vegetaux, Malzeville, France; Julius Kuehn Institute-Federal Research Centre for Cultivated Plants, Institute for Plant Protection in Horticulture and Forests, Braunschweig, Germany; Plant Protection Service, Wageningen, The Netherlands; Central Science Laboratory, York, UK; Walloon Agricultural Research Centre (CRA-W), Department Biological Control and Plant Genetics Resources, Gembloux, Belgium; Settore Fitosanitario, Piemont, Turin, Italy; Plant Protection and Seed Inspection Service (PPSIS), Central Laboratory, Torun, Poland; Agricultural Institute of Slovenia, Ljubljana, Slovenia; and IMEDEA (CSIC-UIB), Esporles, Spain.

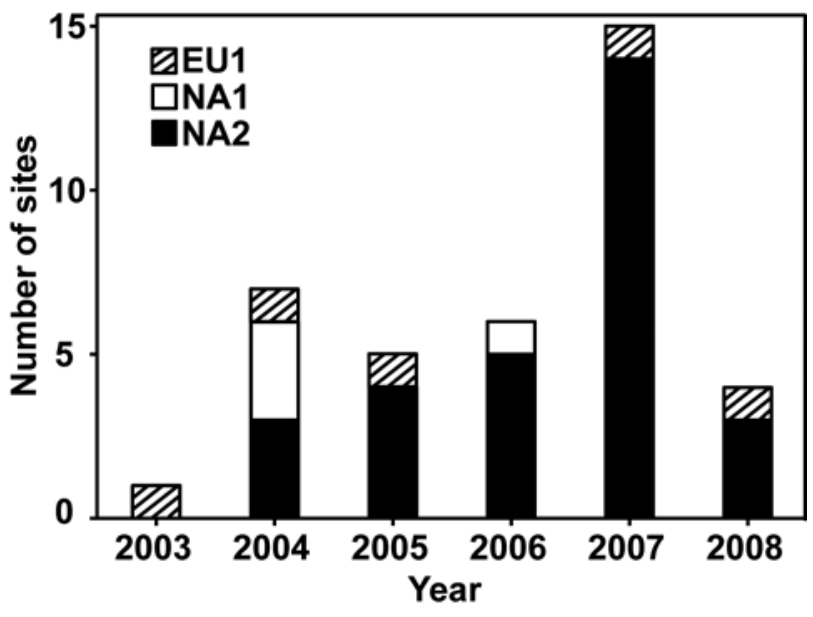

Fig. 1. Clonal lineage of Phytophthora ramorum isolates sampled from nurseries in British Columbia, Canada by year. Both an EU1 isolate and NA2 isolates were collected from a single site in 2007 and five sites are represented in multiple years, two of which had different lineages in different years.

the A2 mating type (Supplemental Table S1). Only 68\% of isolates produced oospores but negative pairings were not repeated, and the production of gametangia in pairings between A1 and A2 P. ramorum isolates is somewhat unpredictable (6).

All NA2 isolates exhibited identical alleles at the loci genotyped (Table 1). Three NA1 multilocus genotypes were found in the sample of five NA1 isolates (Supplemental Table S2). When only the loci that have been genotyped in NA1 nursery isolates from the United States were considered, the three multilocus genotypes from Canada collapsed to two genotypes (Table 1). The NA1 isolates from 2004 shared a common multilocus genotype in the United States that is associated with a large shipment of infected Camellia plants from a California nursery in 2004 (multilocus genotype 1) (Fig. 2A) (10,13). In fact, three of the four 2004 isolates were collected from Camellia spp. The genetic distance between these isolates and the NA1 isolate collected in 2006 was relatively large (Fig. 2A). The 2006 isolate had a rare allele size at PrMS45 (145/186), not previously reported (multilocus genotype "Unique" in Supplemental Table S2). The length of the allele was 21 and $41 \mathrm{bp}$ shorter than the alleles reported from other NA1 isolates from North American nurseries. At other loci, this isolate was identical to a multilocus genotype observed
TABLE 2. Number of sites found with each clonal lineage by host plant (or from soil)

\begin{tabular}{lcccc}
\hline & \multicolumn{3}{c}{ Clonal lineage } & \\
\cline { 2 - 4 } Environment $^{\mathrm{a}}$ & $\mathrm{EU} 1$ & $\mathrm{NA} 1$ & $\mathrm{NA} 2$ & Total sites \\
\hline Camellia & $\ldots$ & 2 & 2 & $3^{\mathrm{b}}$ \\
Cornus & 1 & $\ldots$ & $\ldots$ & 1 \\
Gaultheria & $\ldots$ & $\ldots$ & 5 & 5 \\
Hamamelis & $\ldots$ & $\ldots$ & 1 & 1 \\
Kalmia & $\ldots$ & $\ldots$ & 2 & 2 \\
Leucothoe & $\ldots$ & $\ldots$ & 1 & 1 \\
Magnolia & $\ldots$ & $\ldots$ & 1 & 1 \\
Pieris & $\ldots$ & $\ldots$ & 1 & 1 \\
Pyracantha & $\ldots$ & $\ldots$ & 1 & 1 \\
Rhododendron & 3 & 2 & 9 & $13^{\mathrm{c}}$ \\
Syringa & $\ldots$ & $\ldots$ & 1 & 1 \\
Viburnum & 2 & $\ldots$ & 1 & 3 \\
Soil & $\ldots$ & $\ldots$ & 6 & 6 \\
\hline
\end{tabular}

a Host genus or soil.

b Phytophthora ramorum was isolated from Camellia spp. at site A in two different years: NA1 in 2004 and NA2 in 2008.

${ }^{\mathrm{c}}$ Isolates from the EU1 and NA2 lineages were isolated from Rhododendron spp. at site $\mathrm{O}$ in 2007.

only twice in U.S. nurseries between 2004 and 2007, once in the state of Georgia and once in Oregon (Fig. 2A, multilocus genotype 22) (13). Genotypic diversity was lower in the Canadian sample than in samples from the three West Coast U.S. states (Table 1). Genotypic evenness was similar to Oregon and Washington but higher than the California nursery population, which is dominated by a single genotype.

Four EU1 multilocus genotypes were observed in a ratio of 5:3:1:1. The most common genotype (multilocus genotype A), found at one site in 2003 and a different site in 2004, appears to have been widespread in Europe based on a collection of isolates from the 1990s through 2003 (Fig. 2B; Table 3; Supplemental Table S3). This was also the predominant EU1 genotype in Oregon in 2005. The second most common genotype (multilocus genotype D), found in Canada in 2005 (one isolate) and 2008 (two isolates from one site), was in our European sample at low frequency (one isolate collected in 2002). The singleton multilocus genotype C, collected in 2007, was also present in Europe in 2001 and 2002. The singleton multilocus genotype B, which was collected from the same site as the other 2008 EU1 isolates (Supplemental Table S1, site P), was the dominant EU1 genotype in Oregon in 2003 and 2007 (also collected in 2005, 2006, and 

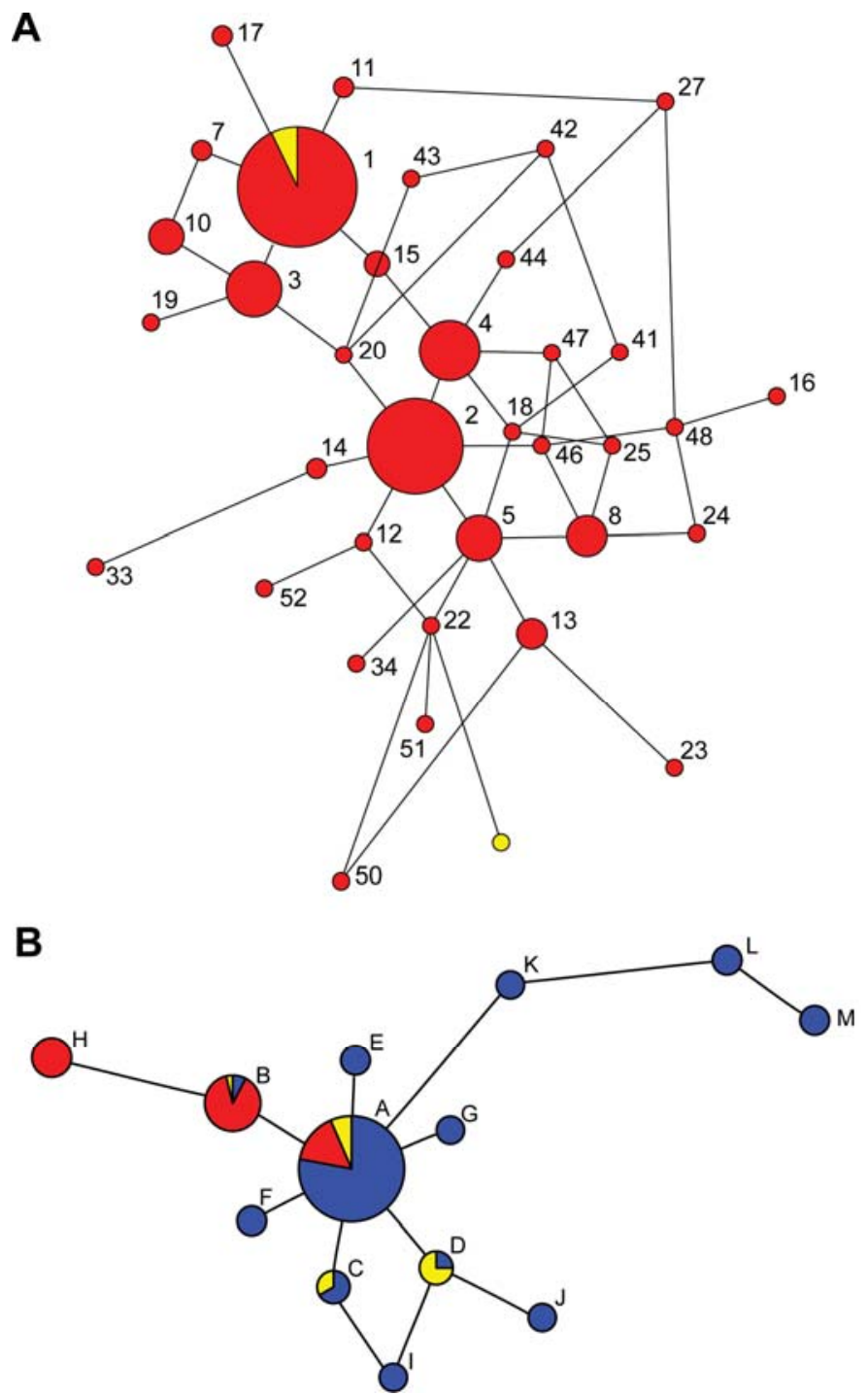

Fig. 2. Minimum spanning networks for A, NA1 lineage multilocus genotypes from Canada and the United States and B, EU1 lineage multilocus genotypes from Canada, Europe, and the United States. Each node (circle) represents a multilocus genotype. Distances between nodes are proportional to Bruvo et al.'s distance (7). Node sizes are rough indicators of frequency and are colored in proportion to their frequency in Canada (yellow), Europe (blue), and the United States (red). A, Multilocus genotypes are numbered as in Goss et al. (13). Canadian isolates were multilocus genotype 1 or a genotype ("Unique") not reported in Goss et al. (13). B, Additional information on the origin of isolates representing each multilocus genotype is given in Table 3 .

2008) but also was detected in Europe in 2003. Genotypic diversity (Stoddart and Taylor's G) in the European sample was 1.63, which was lower than the sample diversities for Canada, Oregon, or California (Table 1). Although more multilocus genotypes were present in the European sample, it was dominated by a single genotype. U.S. samples exhibited lower genotypic diversities and higher evenness than the Canadian sample (Table 1). However, the nature and quality of $P$. ramorum survey data varies greatly between countries and among U.S. states and may affect our inferences.

Bayesian estimates of migration rates for the EU1 lineage were several times higher from Europe to North America than from North America to Europe (Fig. 3A). Theta $(4 \mathrm{N \mu})$ was also inferred to be higher for the European sample than the North American sample, indicating a larger effective population size in Europe under the assumption of equal mutation rates in the two populations (Fig. 3B). Both maximum likelihood runs, with migration from North America to Europe set to zero, produced
TABLE 3. Origin and collection years of EU1 isolates used to construct the minimum spanning network of multilocus genotypes shown in Figure 2B

\begin{tabular}{lclcl}
\hline MG $^{\mathrm{a}}$ & Frequency & Origin & No. of isolates & Years represented \\
\hline $\mathrm{A}$ & 0.60 & Canada & 5 & $2003-2004$ \\
& $\ldots$ & Oregon & 12 & $2005-2006$ \\
& $\ldots$ & Europe & 60 & $1993-2003$ \\
$\mathrm{~B}$ & 0.20 & Canada & 1 & 2008 \\
& $\ldots$ & Oregon & 14 & $2003-2008$ \\
& $\ldots$ & California & 9 & 2008 \\
& $\ldots$ & Europe & 2 & 2003 \\
$\mathrm{C}$ & 0.02 & Canada & 1 & 2007 \\
& $\ldots$ & Europe & 2 & $2001-2002$ \\
$\mathrm{D}$ & 0.03 & Canada & 3 & 2005 and 2008 \\
& $\ldots$ & Europe & 1 & 2002 \\
$\mathrm{E}$ & $<0.02$ & Europe & 2 & 2002 \\
$\mathrm{~F}$ & $<0.02$ & Europe & 2 & 1995 and 2002 \\
$\mathrm{G}$ & $<0.01$ & Europe & 1 & 2003 \\
$\mathrm{H}$ & 0.05 & California & 7 & $2006-2007$ \\
$\mathrm{I}$ & $<0.01$ & Europe & 1 & 2002 \\
$\mathrm{~J}$ & $<0.01$ & Europe & 1 & 2001 \\
$\mathrm{~K}$ & $<0.01$ & Europe & 1 & 2001 \\
$\mathrm{~L}$ & $<0.02$ & Europe & 2 & 2002 \\
$\mathrm{M}$ & $<0.02$ & Europe & 2 & 2002 \\
\hline
\end{tabular}

${ }^{a}$ Multilocus genotype.

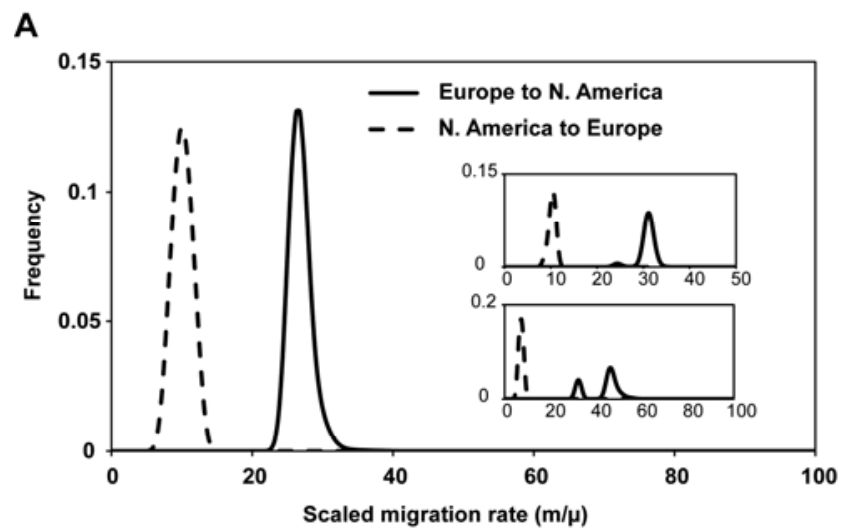

B

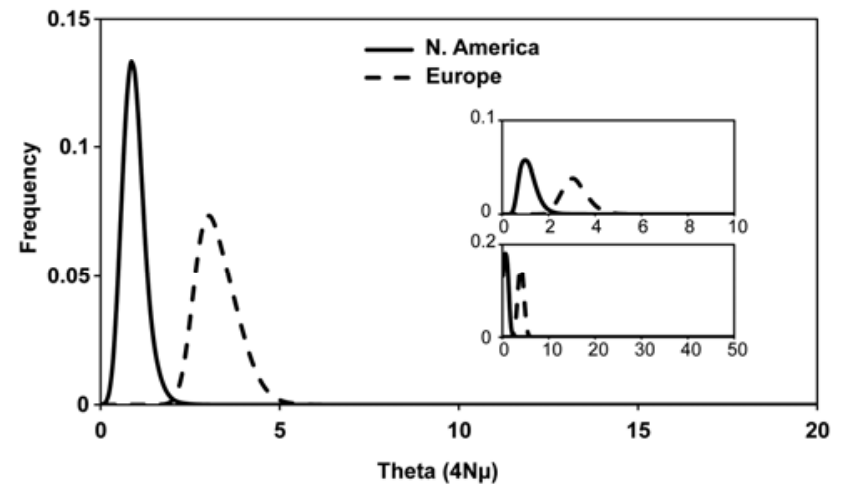

Fig. 3. Estimates of migration rates and population sizes of the EU1 lineage for Europe and North America. Posterior probability distributions for $\mathbf{A}$, mutation-scaled migration rates $(\mathrm{m} / \mu)$ and $\mathbf{B}$, theta, the population-scaled mutation rate $(4 \mathrm{~N} \mu)$, for three Migrate runs (second and third runs shown as inset) using Bayesian inference.

significantly higher likelihoods than the two runs with bidirectional migration (Table 4). AIC also indicated that unidirectional migration from Europe to North America for the EU1 lineage was the more likely migration model (Table 4).

\section{DISCUSSION}

$P$. ramorum has been known to be present in nurseries in British Columbia, Canada since 2003 (8) but this is the first 
TABLE 4. Test of the hypothesis of unidirectional migration from Europe to North America for the EU1 clonal lineage ${ }^{\mathrm{a}}$

\begin{tabular}{|c|c|c|c|c|c|c|c|}
\hline Model & $\theta_{\mathrm{NA}}$ & $\theta_{\mathrm{EU}}$ & $\mathrm{M}_{\mathrm{EU}->\mathrm{NA}}$ & $\mathrm{M}_{\mathrm{NA}->\mathrm{EU}}$ & $\mathrm{LnL}$ & $\mathrm{k}$ & $\mathrm{AIC}^{\mathrm{b}}$ \\
\hline \multirow[t]{2}{*}{ Unidirectional } & 0.46 & 3.94 & 41.38 & 0 & $16.71^{\mathrm{c}}$ & 3 & -27.4 \\
\hline & 0.56 & 3.84 & 37.92 & 0 & 12.02 & 3 & -18.0 \\
\hline \multirow[t]{2}{*}{ Bidirectional } & 0.65 & 3.94 & 32.49 & 8.68 & $9.89^{c}$ & 4 & -11.8 \\
\hline & 0.65 & 3.85 & 35.42 & 8.85 & 8.11 & 4 & -8.2 \\
\hline
\end{tabular}

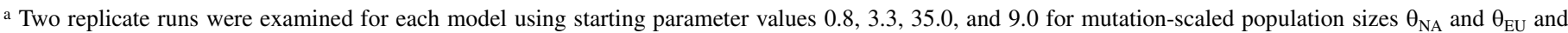
mutation-scaled migration rates $\mathrm{M}_{\mathrm{EU}-\mathrm{NA}}$ and $\mathrm{M}_{\mathrm{NA}->\mathrm{EU}}$, respectively.

b Akaike's information criterion.

${ }^{c}$ Likelihood ratio test using highest likelihood run for each model: $\mathrm{LR}=13.6$, df $=1, P=0.0002$.

analysis of its genetic diversity. Microsatellite genotyping revealed that Canadian nurseries have been infected with all three clonal lineages, which had previously only been observed in Washington State and California (12). Unlike the U.S. data, the NA1 lineage did not represent the majority of Canadian isolates; rather, it was the NA2 lineage. Previously, Washington State was the only locality known to have a resident population of NA2 isolates in its nurseries (13), with occasional reports of NA2 from California. However, as recently as 2007 , the NA1 lineage was more frequently isolated from infected nurseries in Washington than the NA2 lineage (13). These data suggest that the NA2 lineage may be more predominant in British Columbia. This could be significant because the focus of $P$. ramorum research has been on the NA1 and EU1 lineages and much less is known about the virulence properties of the NA2 lineage (16). In addition, the polymorphic microsatellite loci currently used for genotyping $P$. ramorum were designed by screening for variation in the NA1 or EU1 lineages $(17,24,28)$. Only two multilocus genotypes have been observed for NA2 isolates in the United States (13), with the one observed in Canada being the more common of the two. It is unclear whether other markers would exhibit variation in the NA2 lineage or whether this lineage is simply less genetically diverse than the other two lineages. Compared with the other two lineages, it continues to be detected in a more limited geographic range.

Systematic sampling of $P$. ramorum from nursery environments poses a challenge due to its quarantine status, because access to infected sites is restricted. Sampling protocols and intensities vary among localities and among years. Nevertheless, when isolates are available from many sites, they should be representative of the distribution of lineages and the population genetic structure of $P$. ramorum across these sites, and this data can critically inform management of the pathogen. With isolates from 31 sites, our Canadian sample is likely to be representative of the $P$. ramorum population in British Columbia in 2004-2008. At the same time, there is a need for comprehensive efforts integrating nursery sampling, genotype, and phenotype (28).

The EU1 lineage is thought to have been introduced to North America via Europe and our results support this hypothesis. Each EU1 multilocus genotype appears to have been detected in Europe earlier than in North America, with the exception of one genotype from California that was not present in our European sample. Our test of migration did not take year of collection into account; nevertheless, it strongly suggests that migration has been unidirectional from Europe to North America. We are not able to determine at this time whether the introduction or introductions of the EU1 lineage occurred through Canada or the United States or both. EU1 was first identified in both countries in 2003. The EU1 multilocus genotype observed in Canada in 2003 and 2004 is the same multilocus genotype that appeared to be widespread in Europe in the early 2000s and was reported as early as 1993 . The EU1 multilocus genotypes found in Oregon in 2003 differ from these Canada isolates by one repeat unit at PrMS145c. They share this genotype with isolates from Europe collected in 2003; however, this could be convergence because they differ from the dominant EU1 genotype by only a single mutational step. New alleles associated with the dispersal of $P$. ramorum and establishment of new populations appears to be characteristic of $P$. ramorum population structure $(13,21)$. This particular allele has been observed in Oregon through 2008 as well as in California in 2008; thus, a northward migration event may be responsible for the first observation of it in Canada in 2008. Washington EU1 isolates were not included in this analysis; therefore, we do not know how $P$. ramorum infestations in this state may have contributed to the observed distribution of EU1 genotypes.

The USDA-APHIS requires annual inspections of California, Oregon, and Washington nurseries that ship interstate. When a nursery has been confirmed as infested with $P$. ramorum and it has been determined that the nursery shipped potentially infected plants, the nursery is required to provide USDA-APHIS with a list of all host and associated plants that were shipped from the nursery during the preceding 12 months. It is then determined whether the receiving nurseries or landscapes have become infested (trace forward), and the origin of $P$. ramorum in the shipping nursery is similarly investigated (trace back). There were trace forwards from British Columbia to Oregon and Washington each year from 2003 to 2008, as well as British Columbia trace backs to California, Oregon, and Washington (13). In 2004, a large production nursery in California shipped millions of potentially $P$. ramorum-infected camellias to 39 states (10). NA1 isolates collected in Canada in 2004 exhibit the multilocus genotype associated with these shipments (13) and were mostly found on Camellia spp.; thus, these isolates were likely to have originated in California. Another NA1 isolate was identified from 2006, which was highly diverged from the 2004 isolates, differing at four and five loci. Therefore, this isolate is likely to be the result of a second migration event from the United States.

Population genetic variation can provide insights regarding the history and recent movement of pathogens, as has been shown for $P$. ramorum $(12,13,21,23)$. The EU1 lineage was first isolated from nurseries in Europe and this is where most of the genetic variation in the EU1 lineage has been observed $(17,28)$. Likewise, the NA1 lineage was first isolated in the United States and contains enough genetic variation to exhibit clear population structure and migration pathways $(13,21,23,24)$. In comparison, the EU1 and NA1 samples from Canada are less variable and suggest that these clonal lineages are migrants from populations in Europe and the United States, respectively. The NA2 lineage, in contrast, has thus far exhibited very limited polymorphism at the available genetic markers across its known range. The current genetic data are not informative as to whether the NA2 lineage entered North America through British Columbia or Washington. Variable genetic markers for the NA2 lineage are needed to track the movement and uncover the recent history of this clonal lineage.

\section{ACKNOWLEDGMENTS}

This work was supported by funds from USDA-ARS CRIS Project 5358-22000-034-00D, the United States Forest Service Pacific Southwest Research Station Sudden Oak Death research program, and the Belgian Federal Public Service (FPS) "Health, Food Chain Safety and Environment" (project RT-05/04-PHYRAM1). Mention of trade names or com- 
mercial products in this manuscript are solely for the purpose of providing specific information and do not imply recommendation or endorsement. We thank S. Brière for providing the Canadian P. ramorum isolates; all European colleagues for providing European isolates; $\mathrm{K}$. Fairchild, J. Hauffe, K. Henslee, C. Press, and R. Workman for excellent technical support; and G. Chastagner, E. Hansen, and three anonymous reviewers for comments on the manuscript.

\section{LITERATURE CITED}

1. Beerli, P. 2007. Estimation of the population scaled mutation rate from microsatellite data. Genetics 177:1967-1968.

2. Beerli, P. 2009. How to use migrate or why are Markov chain Monte Carlo programs difficult to use? Pages 42-79 in: Population Genetics for Animal Conservation. G. Bertorelle, M. W. Bruford, H. C. Hauffe, A. Rizzoli, and C. Vernesi, eds. Cambridge University Press, Cambridge.

3. Beerli, P., and Felsenstein, J. 2001. Maximum likelihood estimation of a migration matrix and effective population sizes in $n$ subpopulations by using a coalescent approach. Proc. Natl. Acad. Sci. USA 98:4563-4568.

4. Bilodeau, G. J., Lévesque, C. A., De Cock, A. W. A. M., Brière, S. C., and Hamelin, R. C. 2007. Differentiation of European and North American genotypes of Phytophthora ramorum by real-time polymerase chain reaction primer extension. Can. J. Plant Pathol. 29:408-420.

5. Brasier, C. M. 2008. The biosecurity threat to the UK and global environment from international trade in plants. Plant Pathol. 57:792-808.

6. Brasier, C. M., and Kirk, S. A. 2004. Production of gametangia by Phytophthora ramorum in vitro. Mycol. Res. 108:823-827.

7. Bruvo, R., Michiels, N. K., D'Souza, T. G., and Schulenburg, H. 2004. A simple method for the calculation of microsatellite genotype distances irrespective of ploidy level. Mol. Ecol. 13:2101-2106.

8. Elliot, M., Sumampong, G., Varga, A., Shamoun, S. F., James, D., Masri, S., Brière, S. C., and Grünwald, N. J. 2009. PCR-RFLP markers identify three lineages of the North American and European populations of Phytophthora ramorum. For. Pathol. 39:266-278.

9. Excoffier, L., and Smouse, P. E. 1994. Using allele frequencies and geographic subdivision to reconstruct gene trees within a species: molecular variance parsimony. Genetics 136:343-359.

10. Frankel, S. J. 2008. Sudden oak death and Phytophthora ramorum in the USA: a management challenge. Australas. Plant Pathol. 37:19-25.

11. Gansner, E. R., and North, S. C. 2000. An open graph visualization system and its applications to software engineering. Software Pract. Exp. 30:1203-1233.

12. Goss, E. M., Carbone, I., and Grünwald, N. J. 2009. Ancient isolation and independent evolution of the three clonal lineages of the exotic sudden oak death pathogen Phytophthora ramorum. Mol. Ecol. 18:1161-1174.

13. Goss, E. M., Larsen, M. M., Chastagner, G. A., Givens, D. R., and Grünwald, N. J. 2009. Population genetic analysis infers migration pathways of Phytophthora ramorum in US nurseries. PLoS Pathol. 5:e1000583.

14. Grünwald, N. J., Goodwin, S. B., Milgroom, M. G., and Fry, W. E. 2003. Analysis of genotypic diversity data for populations of microorganisms. Phytopathology 93:738-746.

15. Grünwald, N. J., Goss, E. M., Ivors, K., Garbelotto, M., Martin, F. N., Prospero, S., Hansen, E. M., Bonants, P. J. M., Hamelin, R. C., Chastagner, G. A., Werres, S., Rizzo, D. M., Abad, G., Beales, P. A.,
Bilodeau, G. J., Blomquist, C. L., Brasier, C. M., Brière, S. C., Chandelier, A., Davidson, J. M., Denman, S., Elliot, M., Frankel, S. J., Goheen, E. M., de Gruyter, H., Heungens, K., James, D., Kanaskie, A., McWilliams, M. G., Man In'T Veld, W. A., Moralejo, E., Osterbauer, N. K., Palm, M. E., Parke, J. L., Perez Sierra, A. M., Shamoun, S. F., Shishkoff, N., Tooley, P. W., Vettraino, A. M., Webber, J. F., and Widmer, T. L. 2009. Standardizing the nomenclature for clonal lineages of the sudden oak death pathogen, Phytophthora ramorum. Phytopathology 99:792-795.

16. Grünwald, N. J., Goss, E. M., and Press, C. M. 2008. Phytophthora ramorum: a pathogen with a remarkably wide host-range causing sudden oak death on oaks and ramorum blight on woody ornamentals. Mol. Plant Pathol. 9:729-740.

17. Ivors, K., Garbelotto, M., Vries, I. D., Ruyter-Spira, C., Te Hekkert, B., Rosenzweig, N., and Bonants, P. 2006. Microsatellite markers identify three lineages of Phytophthora ramorum in US nurseries, yet single lineages in US forest and European nursery populations. Mol. Ecol. 15:1493-1505.

18. Ludwig, J. A., and Reynolds, J. F. 1988. Statistical Ecology: A Primer on Methods and Computing. John Wiley \& Sons, New York.

19. Martin, F. N. 2008. Mitochondrial haplotype determination in Phytophthora ramorum. Curr. Genet. 54:23-34.

20. Mascheretti, S., Croucher, P. J. P., Kozanitas, M., Baker, L., and Garbelotto, M. 2009. Genetic epidemiology of the Sudden Oak Death pathogen Phytophthora ramorum in California. Mol. Ecol. 18:4577-4590.

21. Mascheretti, S., Croucher, P. J. P., Vettraino, A., Prospero, S., and Garbelotto, M. 2008. Reconstruction of the Sudden Oak Death epidemic in California through microsatellite analysis of the pathogen Phytophthora ramorum. Mol. Ecol. 17:2755-2768.

22. McCullough, D. G., Work, T. T., Cavey, J. F., Liebhold, A. M., and Marshall, D. 2006. Interceptions of nonindigenous plant pests at US ports of entry and border crossings over a 17 -year period. Biol. Invasions 8:611-630.

23. Prospero, S., Grünwald, N. J., Winton, L. M., and Hansen, E. M. 2009. Migration patterns of the emerging plant pathogen Phytophthora ramorum on the west coast of the United States of America. Phytopathology 99:739-749.

24. Prospero, S., Hansen, E. M., Grünwald, N. J., and Winton, L. M. 2007. Population dynamics of the sudden oak death pathogen Phytophthora ramorum in Oregon from 2001 to 2004. Mol. Ecol. 16:2958-2973.

25. Rizzo, D. M., and Garbelotto, M. 2003. Sudden oak death: Endangering California and Oregon forest ecosystems. Front. Ecol. Environ. 1:197204.

26. Rizzo, D. M., Garbelotto, M., and Hansen, E. M. 2005. Phytophthora ramorum: integrative research and management of an emerging pathogen in California and Oregon forests. Annu. Rev. Phytopathol. 43:309-335.

27. Stoddart, J. A., and Taylor, J. F. 1988. Genotypic diversity: Estimation and prediction in samples. Genetics 118:705-711.

28. Vercauteren, A., De Debbelaere, I., Grunwald, N. J., Bonants, P., Van Bockstaele, E., Maes, M., and Heungens, K. 2010. Clonal expansion of the Belgian Phytophthora ramorum populations based on new microsatellite markers. Mol. Ecol. 19:92-107.

29. Werres, S., and Kaminski, K. 2005. Characterisation of European and North American Phytophthora ramorum isolates due to their morphology and mating behaviour in vitro with heterothallic Phytophthora species. Mycol. Res. 109:860-871. 